\title{
Assessing the Image: Creative Practice in an Online Learning Environment
}

\author{
Dr. Anna Nazzari, Gina Cinanni, Moira Doropoulos, Curtin University, Australia
}

\begin{abstract}
Academics who work in the field of online art education are frequently asked the question, 'How do you assess art online?' The view that art cannot be assessed through a digital interface stems in part from a Kantian perception of art as a product that is aesthetically evaluated via the senses in a physical space. In this presentation, we will establish that assessing art in an online learning environment requires an understanding of the multiple roles the digital image assumes. This will be illustrated through a consideration of the digital image as a repository of data that must visually promote doing and thinking. In the context of art online, doing and thinking 'are acts (and forms) of critique' by which the assessor can evaluate competence of skill and judgment. As evidence of experimentation, reflection and interpretation of creative practice, the image acts as proof of the existence of the work and the authenticity of the author. Under the colloquium's theme of 'Images in the Service of Learning', the digital image will be positioned as a vital contemporary tool which has the power to shift and enhance how we see, experience and contextualize art in an eLearning environment.
\end{abstract}

Keywords: Arts, Assessment, eLearning

$\mathrm{F}$ or over twenty years and in various incarnations, academics at Curtin University in Perth, Western Australia, have been teaching a BA (Fine Art and Visual Culture) degree online. As this length of time attests online art education is far from a new venture, yet in spite of large enrolment numbers and increasing recognition of online study the question, "how do you assess art online" still persists. The uncertainty of whether or not art can be adequately appraised through digital interfaces stems from a delay in acknowledging that digital technologies help generate learning experiences that are different to traditional art education. For those familiar with a traditional face-to-face learning system, issues of conflict arise from the belief that the assessment of an artwork should involve a direct encounter with an artwork. In this system the digital image is not considered a trustworthy measure of evaluating some forms of art and the layout of images within the digital space allegedly creates prescriptive art outcomes. For those accustomed to a digital learning space, online art education is far from substandard in comparison to other models of art education; it is simply a different model. In this space, the digital image exists as the principal communicator of all assessable visual inquiry. As an art form and a repository of data it must visually promote doing and thinking that not only verifies the existence of an artwork but also the authenticity of the author. Assessing a work of art in a digital space thus requires recognition that the artwork is not independent of its digital mode of delivery but rather needs to operate within it in order to shift and enhance how we see, experience and contextualise art.

Late twentieth century technological advances provided the momentum for the materialization of online education. Digital imaging was first established in the 1960s when NASA converted their space probes from analogue to digital so that they could map the surface of the moon and send digital images back to earth. By the mid-1970s the global communications system ARPANET, which enabled digital messaging from one network to connect with a network of networks, became operational. The arrival of the home computer in the 1970s and its subsequent popularity in the 1980s with the expansion of graphics software and computer games, led to the development of the Internet in the 1990s. The World Wide Web, a system of interlinked hypertext documents accessible via the Internet, followed in 1991. An explosion of other technologies such as digital cameras, ink jet printers, webcams and a range of more sophisticated computer softwares all began to form part of the larger digital technology interface. With the invention of the Internet and the World Wide Web, individuals could now inexpensively manage, provide, source and use information for themselves or share with anyone from all over the world. In educational institutions, this unprecedented treatment of, and access to, information sparked a whole new way of learning which facilitated the birth of the online elearner: a person learning via electronic study materials, tutor and peer discussion boards, websites, email and digital and audio interfaces.

In the article Virtual Art Education: Is it Possible?, Mahizer Hamzah and Adnan Abd Azia discuss how the Internet has specifically impacted on art related courses and altered the way art educators, researchers and students utilise digital technologies to "find, manage and use information, transforming social interactions and posing new challenges both in and out and of the classroom" (Hamzah and Azia, 2012). In a time of exponential growth in online education, understanding these challenges is particularly relevant as universities are providing more online content and learners are demanding more access to knowledge through cost effective methods. This can be seen through the ever-growing popularity of MOOCs (Massive Open Online Courses).

\section{The Institutional Context}


In this investigation, the assessment of images in an online learning environment is restricted to the field of art practice and uses Curtin University as an experiential model. While the issues raised in this paper may be specific to the experiences and observations of Curtin academic staff teaching art in an online environment, it is envisaged that the discussion will be relevant for other institutions assessing art online or entering into the realm of art online education.

In Australia, Curtin University offers the only fully online art degree and in a country of vast geographic expanse, in which students often have to travel to study, online education is practical, flexible and offers unparalleled learning opportunities. The BA (Fine Art and Visual Culture) is equivalent to the on-campus course, in that students studying online must meet the same learning requirements to receive the same degree on completion and graduation.

In the degree, students can choose from a range of visual culture, visual studio workshop and visual arts research units. Of these choices, it is often the representation of the traditional fields of art such as printmaking, drawing, textiles, painting and sculpture as well as the art project units, which involve self-directed study, that provoke the most speculation in regard to assessment. The conjecture concerning the nature of how one assesses art online is directly and indirectly connected to the technologies used in this environment. In Digital Technology in the Visual Arts Classroom: An [un]Easy Partnership, Judith Wilks, Alexander Cutcher and Susan Wilks (2012) note that an idea of material practice is pivotal to visual arts education. They cite Marshall McLuhan's famous quote "the medium is the message" to suggest that artworks constructed through the use of information communication technologies, have radically altered the way "the message," of materiality is communicated and understood. Thus, it is often issues connected with a sense of what art is and how it should be communicated that reinforce the idea that digital technologies efface art education rather than provide an alternative way of teaching and learning about art.

For elearners studying studio workshop or arts research units in this degree, the majority of assessments will require them to submit a folio of work. Depending on the students' level of study the folio may include a series of completed tasks or a series of outcomes based on a proposed area of investigation. All folios need to contain evidence of visual diary work including idea development, artist and other research, material and process exploration and any unresolved outcomes. Students are also required to submit their folios digitally in an appropriate presentation format such as PowerPoint presentations. In these presentations, the visual data is expressed via digital images, which typically consists of scanned material such as visual diary pages, photographic documentation of outcomes and explorations, digitally generated artworks as well as images sourced from the Internet such as artist or other research. Although, all students will include notes in their presentations, the digital image is the main communicator of all assessable visual inquiry.

\section{The Image in Digital Space}

Digital images share the basic DNA of all images in that, as Vilém Flusser wrote In Towards a Philosophy of Photography, 'Images signify - mainly - something 'out there' in space and time that they have to make comprehensible to us as abstractions (as reductions of the four dimensions of space and time to the two surface dimensions)" (Flusser 2000,8). Unlike images viewed in a non-digital space, the digital image is an electronic abstraction of visual information that has been photographed or scanned and can only manifest in a digital space. When assessing submissions, the computer acts as a digital depot in which digital technologies merge to make the interaction with digital images possible. The assessment platform for most works is therefore subject to the dimensions of a computer ${ }^{1}$ screen. The screen, and its dimensions, must then reveal information abstracted from specific times and spaces and project them back into contemporary space and time in order to convey meaning.

Interpreting the content of the digital image through the constraints of the digital depot is generally the first issue of conflict for those questioning the merits of online art education provided by Curtin. Adverse speculation arises from a belief that it must be impossible to adequately assess an artwork in a digital space if one cannot fully experience the artwork. This attitude relegates the role of the digital image to one of documentation only, and positions it as a reinforcement of the depot's technological barrier, which is perceived as immobilising a person's direct assessment of an artwork. It also signals a delay in recognising that there are differences between the assessments of "on campus" and "online" artworks and that these differences are not necessarily inferior, they are just alternative ways of experiencing art and making meaning.

\footnotetext{
${ }^{1}$ We also use a large flat screen monitor for final studio presentations.
} 


\section{Defining Aesthetics}

The idea that an assessment of an artwork should involve a physical encounter with an artwork can be linked to aesthetics theories that primarily focus on the appreciation of beauty and good taste. According to Mark Johnson's book, The Meaning of the Body: Aesthetics of Human Understanding (2007) this distinction is the most pronounced in the aesthetic theory of Immanuel Kant. In the Critique of Judgement (1790), Kant scrutinised the prescribed constitutions of both aesthetic judgement and art-making through the notions of free play of imagination and understanding. Johnson suggests that although Kant was instrumental in identifying the frequency of amalgamations between imaginative-feeling-thinking-processes which inform how we experience meaning, he was never able to relinquish his engineering of cognitive functions, and so never fully acknowledged the role the mind, thought and language played in this assessment. Johnson asserts that Kant's faithfulness to an eighteenth century faculty of psychology that rigorously differentiated cognitive from non cognitive mental acts meant that he failed to consider imagination and feeling as intelligible parts of an artwork's meaning and comprehension.

Kant's most reductive view stipulated that the detection of beauty necessitated a type of "disinterested judgement" capable of shelving one's practical, political and ethical beliefs. This idea persisted well into twentieth century aesthetic discourse through the facade that it was an essential condition for a genuine aesthetic study of art. Theorist, Frank Sibley, for example expressed a similar view in his paper Aesthetic and Non Aesthetic:

People have to see the grace or unity of a work, hear the plaintiveness or frenzy in the music, notice the gaudiness of colour scheme, feel the power of a novel, its mood, or its uncertainty of tone. They may be struck by these qualities at once, or they may come to perceive them only after repeated viewings, hearings or readings and with the help of critics. But unless they do perceive them for themselves, aesthetic enjoyment, appreciation and judgement are beyond them. Merely to learn from others on good authority, that the music is serene, the play moving or the picture unbalanced is of little aesthetic value; the crucial thing is to see, or hear, or feel.

To suppose that one can make aesthetic judgements without aesthetic perception, say, by following rules of some kind, is to misunderstand aesthetic judgment. (Sibley 2001, 598)

Sibley's position suggests aesthetic encounters involve instantaneous, non-inferential sensory reactions that are enhanced by continuous reflection and not by the influence of other substantial factors deriving from art theory, art practice or art history. His stance implies aesthetic judgement is autonomous and reliant specifically on the faculty of sensation: the recognition of sense data such as sights, sounds, tastes, smells and tactile impressions and the faculty of feeling: the experience of pleasure and pain produced from sensory reactions. Consequently, it is often this outmoded and linear perception of aesthetics which elevates the direct encounter as essential in the evaluation of an artwork that is knowingly/unknowingly referenced by those implying that a digital space is an impediment to assessing an artwork.

This form of aesthetic judgement is not congruent with Curtin University's assessment ethos largely because it does not recognise the digital space as capable of eliciting an aesthetic encounter. In The Border of the Aesthetic, Robert Gero suggests that, "any property of an artwork counts as an aesthetic if its virtual "viewing" is sufficient to generate non-inferential judgements" (Gero 2005, 15). He believes that the cognitive contents of an artwork such as thoughts and ideas can invoke aesthetic reactions. An example of this can be gleaned from the Museum of Non Visible Art (MONA), a collaborative project by James Franco and conceptual art duo Praxis. Their interactive museum is founded exclusively on ideas and patrons can participate by purchasing a description of a non visible artwork. The descriptions are designed to be affective, that is move the viewer through imagination, humour, audacity, and beauty. Consequently, if thoughts can generate intuitive or visceral responses, it would be nonsensical to suggest that this experience is absent from a digital viewing platform. In an online education setting, even with the limitations of a computer screen one can still see, hear or have an emotional response to a digital image of an artwork or even a digital image that is only describing ideas and practical development. It is important to note that, "New technologies suggest different forms, contexts and frameworks" (Wilks, Cutcher and Wilks 2012, 56), therefore an understanding of the digital image viewed through the digital interface, is part of the critical experience required of the assessor engaged in online teaching and learning.

It is also worth highlighting that it is unlikely that an aesthetic encounter with an artwork could logically be removed from its theoretical properties. Gero suggests that a work assessed solely via sensory or felt based responses would only permit subjective assessments defined by one person's tastes (Gero 2005). Therefore, if 
aesthetics plays a role in the assessment of digital images it occurs as part of a greater dialogue that positions an aesthetic encounter as not only informed by what one sees, hears or feels but also governed by other meanings and contexts such as details about art history, art theory and art practice.

The belief that it must be impossible to adequately assess an artwork in a digital space if one cannot fully experience the artwork is only one part of the delay in recognising that new technologies generate different learning experiences to that of traditional art education; the other relates to assessing the authenticity and value of information communicated in the digital image. From the point of view of Curtin staff teaching art online, the doubts surrounding the accuracy of data conveyed in digital images is compounded by a lag in grasping how new technologies have spawned a digital visual literacy that endorses different ways of viewing, analysing and perceiving art.

\section{Visual Literacy}

According to Stephen Apkon, in The Age of the Image: Redefining Literacy in a World of Screen, since the implementation of the Internet and the World Wide Web, it has become increasingly evident that humans live in a world saturated with images. This abundance of visual imagery not only denotes the advances of technology via its capacity to share and disseminate a wealth of information but also, from a theoretical premise, it specifies a new way of being literate. In this age, Apkon indicates, “. . . we are physiologically constructed to consume and find meaning from images in a way that transcends other forms of communication" (Apkon 2013, 13).

In general, literacy refers to the knack of communicating successfully through the text of the time: the most widespread mode of expression in any given specific society. To be literate is to be well-versed in the most prevailing and meaningful language of the day (Apkon 2013). Apkon asserts that, "True literacy is always a two-way transaction. We don't just consume; we produce. We don't just read; we write. The ability to receive information is always the first part of the literacy equation that is necessary for the masses, and then the ability to express information generally follows" (Apkon 2013, 41). This new way of being literate through "image communication' has resulted in changes in methods of communication for both the individual and the institution.

Evidence of a new visual literacy is already apparent in the contemporary art world, where the digital image is a visual marker of an artist's or museum's ability to successfully communicate information. Artists repeatedly disseminate their work through the digital image: in submissions to be considered for exhibitions and awards; in applications for funding and public projects; and via websites and blogs which give international exposure to work that might otherwise only be seen by a local audience. Likewise, museums actively promote and disseminate their collections and projects to a global audience through the same digital interface, while further encouraging access to different ways of experiencing visual art through digitally printed merchandising designed to find its way into the domestic realm. As students, elearners typically sit outside of this model of professional practice however, before enrolling in an online course most have been actively living with and absorbing images through exposure to social media, websites and blogs. Being literate in this field of study requires students to gain knowledge and experience with the tools of their discipline.

In online art education, the elearner is not only a consumer of visual literacy but also a producer. In Digital Visual Literacy, Anne Morgan Spalter and Andries van Dam define digital visual literacy as the ability to:

1. Critically evaluate digital visual materials (two-dimensional, three-dimensional (3D), static, and moving);

2. Make decisions on the basis of digital visual representations of data and ideas; and

3. Use computers to create effective visual communications. (Spalter and van Dam 2008, 94)

As a consumer and producer a student studying the BA (Fine Art and Visual Culture) needs to be visually literate. This involves being able to use a computer to generate effective visual communications; critically evaluate and creatively respond to learning materials; make decisions based on their research, ideas and creative explorations; capture or store all of their production, both developmental and resolved, via digital images and present this information in a communicable format. Often, it is the communication of "producibility" in the digital image that raises the most speculation in regard to assessment at Curtin. Spalter and van Dam assert that, 
"the ease with which digital images can be altered to create fauxtography means that we must become much more critical interpreters of visual information" (Spalter and van Dam 2008, 94). Their view acknowledges that there are difficulties associated with assessing an artwork, especially when the digital image can easily be altered to create fauxtographic versions of creative practice. From the perspective of Curtin online art educators, this position points to a continued comparison to, and elevation of truths associated with past imaging technologies and a delayed acceptance of the digital image in online art education as a valid medium within its own right.

\section{Indexicality}

To comprehend Curtin's position, it is important to consider the role of indexicality. In Digital and Other Virtualities: Renegotiating the Image, Antony Briant and Griselda Pollock suggest that a distrust of digital images as artworks or conveyors of meaningful data stems from an inability to forensically navigate the digital image in the same way as past photographic or 'analogue' images (Briant and Pollock 2010). In On Photography, Susan Sontag writes, "Photographs furnish evidence. Something we hear about, but doubt, seems proven when we're shown a photograph" (Sontag 1977, 5). She noted that although photographs are distortions of reality there is an assumption that something exists, or did exist at one point in time (Sontag 1977). This postulation of existence is not just based on trace evidence of other realities but, as Brian and Pollock indicate, a perception that the production of the analogue image is connected to the event, both via the image that results and the experience of time and place it proffers. This feature, typically associated with analogue images rather than digital, is known as indexicality.

Indexicality refers to those media, such as film or photography, in which the production of signs involves traces of the real objects they represent. In Camera Lucida: Reflections on Photography Roland Barthes highlights this point by suggesting that a photograph is never discernible from its referent:

By nature, the photograph . . . has something tautological about it: a pipe, here is always intractably a pipe. It is as if the photograph always carries its referent with itself, both affected by the same amorous or funeral immobility, at the very heart of the moving world: they are glued together, limb by limb, like the condemned man and the corpse in certain tortures. . The photograph belongs to that class of laminated objects whose two leaves cannot be separated without destroying them both: the window pane and the landscape, and why not: Good and Evil, desire and its object: dualities we can conceive but not perceive. .. (Barthes 1981, 6)

Barthes suggests that there is no photograph that cannot contain trace evidence of something or someone because there is always a connection between the photo image and its event. Conversely, in Change Mummified: Cinema, Historicity, Theory, Phillip Rosen notes that although the digital camera draws light like a traditional camera it does not register its existence by chemical reactions on photosensitive material. Rather it is an apparatus for programming the degree of light as numbers on a magnetised substrate and the captured image is made up of pixels with determined colour values organised via Cartesian coordinates. The digital image is an arrangement of numbers in binary sets, which Rosen suggests, means numbers rather than light sensitive materials are the key intervening materiality. Thus, without straightforward indexical roots, the digital image is often described as a simulated photographic representation that mirrors analogue photography but in reality, exists as its "Other" (Rosen 2001).

Unlike analogue photography, there is also belief that digital images do not have clear profilmic origins that prescribe a "here and now-ness" or a "there and then-ness" often associated with another aspect of indexicality: deixis. Briant and Pollock suggest that deixis in photography generates questions of perception, experience or knowledge of the present, a living historical as well as pragmatic perception of the world, identification of who we are, otherness and relationships to time and space (Briant and Pollock 2010).

\section{Authenticity of the Image}

For those questioning whether it is possible for online art educators to assess the authenticity of information communicated in the digital image, it is often the perceived sense of loss stemming from analogue photography's indexicality that informs this decision. One of the major points of contention arises from the fact that digital images are composed of numbers and not physical substances which means that with the simple aid of a computer software program they can be altered to make endless image configurations. Consequently, from the experiences of Curtin online art educators, questions levelled at this issue usually centre on the "truthfulness" of what is actually being assessed if, after the work is documented, there is a perception it can be altered. 

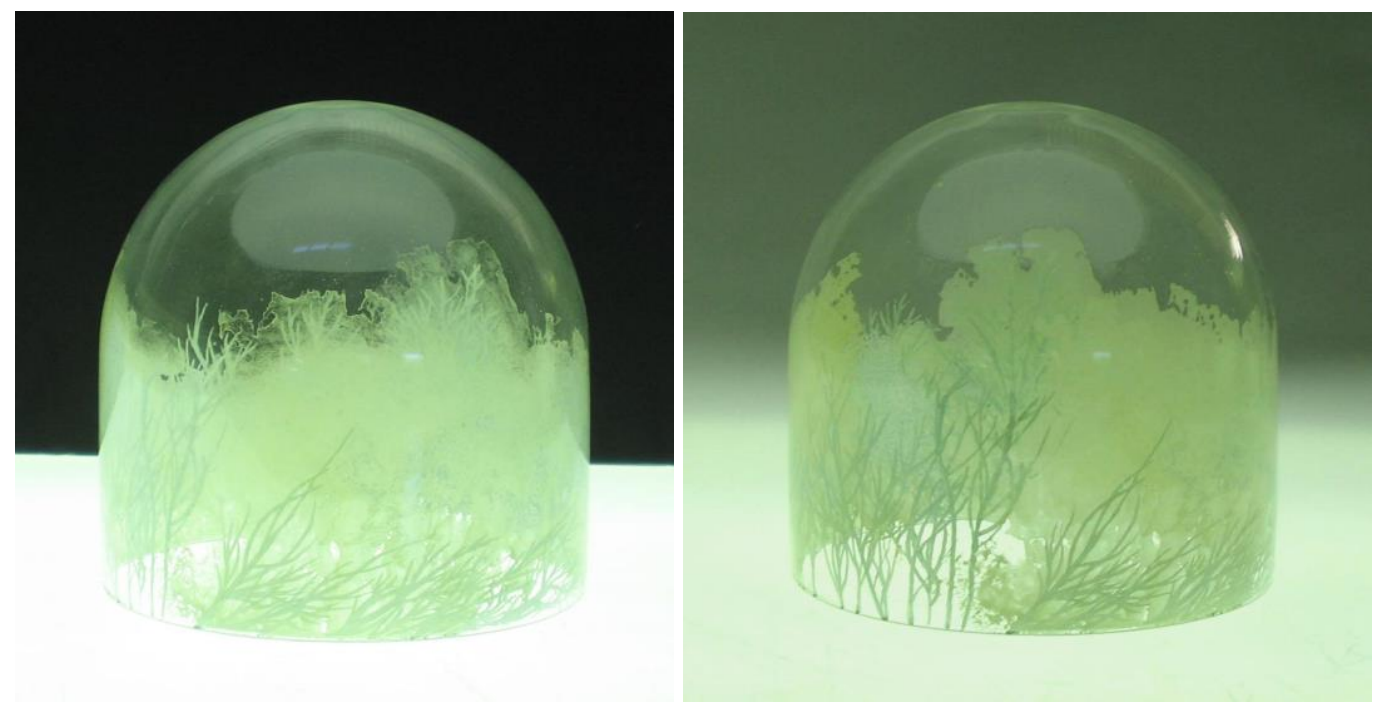

Figure 1: Student A exemplar, Paradise lost-dust, gouache on glass dome

\section{Source: Curtin SoDA Art OUA_Student Learning Resources}

An anecdotal example of this perceived loss of "truthfulness" comes from a recent final year assessment of student work. During the assessment of Student A's sculptural work (fig. 1), one of the external assessors remarked, "This work looks great, but I know it has a lot to do with how it has been documented and digitally manipulated, I doubt I would like this if I saw it in the flesh." The external assessor's remarks illustrate a reoccurring question levelled at this mode of study: Can I trust what I am seeing is the actual artwork? Can I trust that what I am seeing is a true representation of the artwork? This question instantly challenges the authenticity of the artwork and creator by querying if the work is a documentation of an actual event or an actual artwork; if the image belongs to a real time and space; if it is a legitimate act of doing or if a sense of here-andnow-ness in direct reference to what has been captured at a specific time and space is believable. In doing so, it fatefully compares the digital image to notions of indexicality associated with the analogue image, legitimises a direct encounter with an artwork and in turn suggests that the student is being advantaged through the technowizardry associated with the digital image's endless manipulable qualities.

In regard to the infinite picture making possibilities of the digital image, the external assessor's remark fails to acknowledge that making meaning in online learning is not limited to the documentation of a physical outcome such as a painting or a sculpture but can continue through the manipulation of the digital image. After the initial documentation, a digital image may have undergone several computer graphic enhancement processes: its brightness, intensity, colour and contrast may have changed; new layers may have been added, the background may have been altered, unwanted components may have been removed, additional graphics may have been included, the image may have been cropped, the view/perspective may have been changed and so forth. The reality that an assessor is rarely ever likely to see an artwork in the flesh should not be viewed as a negative. The technologies enabling the manipulation of the digital image give students an opportunity to explore the boundaries between the documentation and/or enhancement of documentation as part of the artwork itself. Thus, for Curtin online assessors, the digital image is not just a tool for students to document or deliver their artwork but also a medium for exploration and extension of art practice and needs to be viewed holistically as evidence of effective visual literacy in this environment

It is also worth noting, as Spalter and van Dam suggest, that "It is not just abilities such as altering images in Photoshop ... that make computer graphics revolutionary - it is the computer's ability to provide a discrete and abstract language for representing visual information" (Spalter and van Dam 2008, 94). In this way, the loss of truthfulness that is often aligned with the computer's radical ability to reproduce and share digital images may be exacerbated through a lack of understanding of its abstract language.

Questions of authenticity may also be raised in the digital image in relationship to who is the author of the artwork. In an online setting, an artwork that has been digitally generated may be constructed from a wide range of source material that is not necessarily photographed by the student. In Student B's work for example, 
extracted from the series Glitches in the Made Tricks (fig. 2) the image is primarily constructed from a range of sourced historical, contemporary cultural, political and kitsch images from the Internet. This does not make the work any less authentic, in fact it enables the student to extend the potential of creative production via access to an infinite palette of 'raw material' for the development of the artwork.

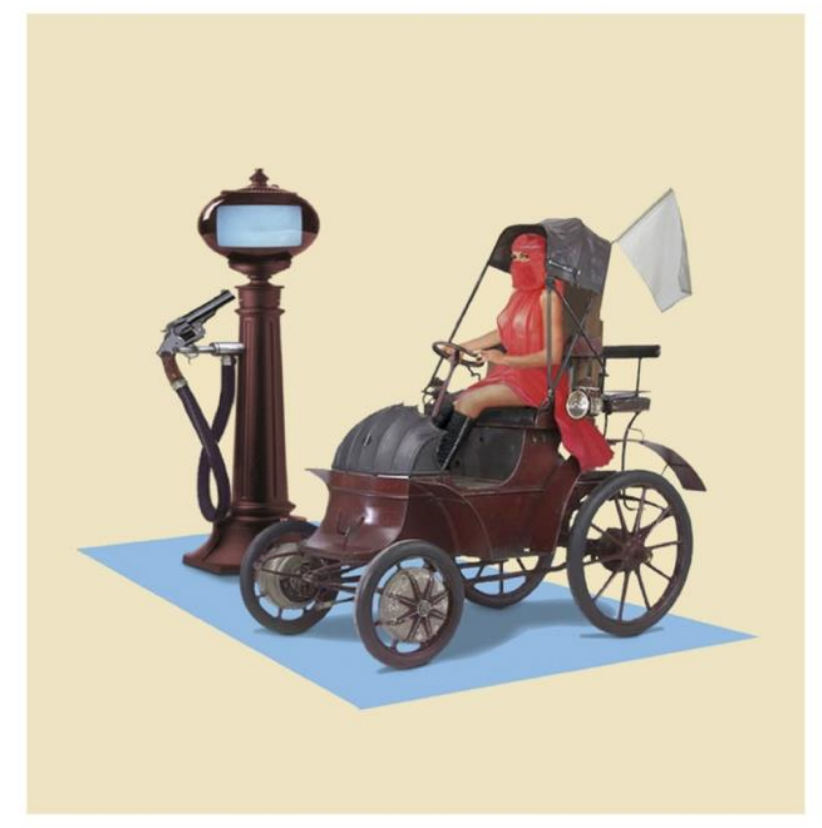

Figure 2: Student B exemplar, from the series Glitches in the made tricks, digital collage

\section{Source: Curtin SoDA Art OUA_Student Learning Resources}

In regard to the authenticity of digital images, it is worth noting first that Rosen suggests digital images do contain something very comparable to the profilmic concept of indexicality in that digital images do not eradicate referential origins. He infers if a digital image did not contain ". . .referential entities or events preexisting the data itself, then the data would have no informational value. .." (Rosen 2001, 307). Therefore, all digital images contain notional referents that make their content recognisable even if this is only through a very cursory reference to the digital image itself (Rosen 2001).

For Curtin online assessors, evaluating the authenticity of an artwork expressed via a digital image typically occurs through a process of how much or how little a student effectively communicates in the image they provide. In this sense, authenticity is garnered through evidence of meaning and context. In Making Art: Form and Meaning, Terry Barrett notes "Meaning is an elusive term, but it generally refers to what an artwork is about or what it expresses" (Barrett 2011,20). He asserts that the meaning of an artwork is always contingent on context: the conditions and circumstances which structure its setting. In any work of art the conditions and circumstances will fluctuate, from where, how and why an object is positioned in a certain location, to how the object or its components interact, to the artist's own personal experience and their relationship with the past, present or future conditions that shape the understanding of their artwork (Barrett 2011). Extrapolating meaning and context from an artwork is a good way of determining clarity, originality and inventiveness, all of which help verify the authenticity of the creator and the artwork.

An understanding of authenticity, in relation to meaning and context, is also determined through substantiation of "doing" and "thinking". In this respect, no image is assessed in isolation and all material supporting the digital image must visually promote doing and thinking, both in the act of producing, and in the resolution of production. In an online submission, digital images must show evidence of a student's brainstorming, experimentation, reflection, development, extension and resolution of creative practice. In other words, digital images must express meaning and context, both individually and collectively through the communication of a form of critical reasoning that discloses cognitive abilities and pressing concerns in relation to the ideas, materials and processes being investigated. Generally speaking, if this information is absent from a 
submission or does not clearly relate to the information communicated in a digital image, then questions of authorship will be raised.

In regard to Students B's digitally generated image, the small sample of images below (fig. 3), which have been extracted from his visual diary, highlight some of his practical decision making but also verify the origins of his own doing and thinking which helps to legitimise the work as original and authentic to the author.
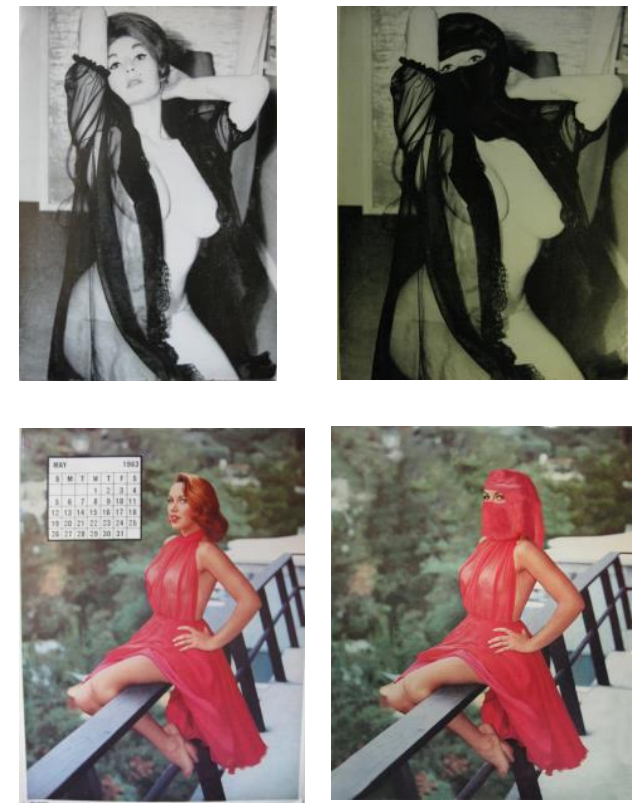
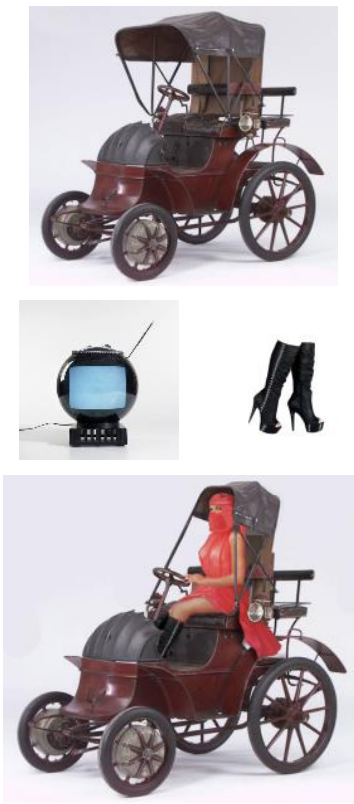

Figure 3: Student B exemplar, developmental workings for Glitches in the made tricks

Source: Curtin SoDA Art OUA_Student Learning Resources

\section{Narrative}

Another issue of contention often raised is that the layout of assessment creates a formulaic narrative that allows no room for ambiguity in its disclosure of development and outcomes. It is fair to say that an idea of narrative penetrates art online learning in a more literal sense than traditional face-to-face teaching. In most oncampus assessment reviews, for example, assessors will view an artwork set up in a specific location and in the near vicinity will be some additional support material accompanying the main artwork/s such as research, visual diary, material tests and so forth. Usually there is no specific ordering or arranging of this information and although an assessor may sift through this material to determine or discover the origins and development of the work, generally though, the final artwork is the central focus.

By contrast, the arrangement or ordering of information in a digital submission is typically laid out in a linear fashion from start to finish. Digital images are inserted into a digital PowerPoint presentation sequentially (refer fig 4) which means the distinction between preliminary development and final outcomes may be little more than a titled slide. This mode of presentation instantly creates a visual narrative which encompasses a series of short tales plotting the beginning, middle and end of set exercises or a longer allegory highlighting the inventions and discoveries of a self-directed project. 


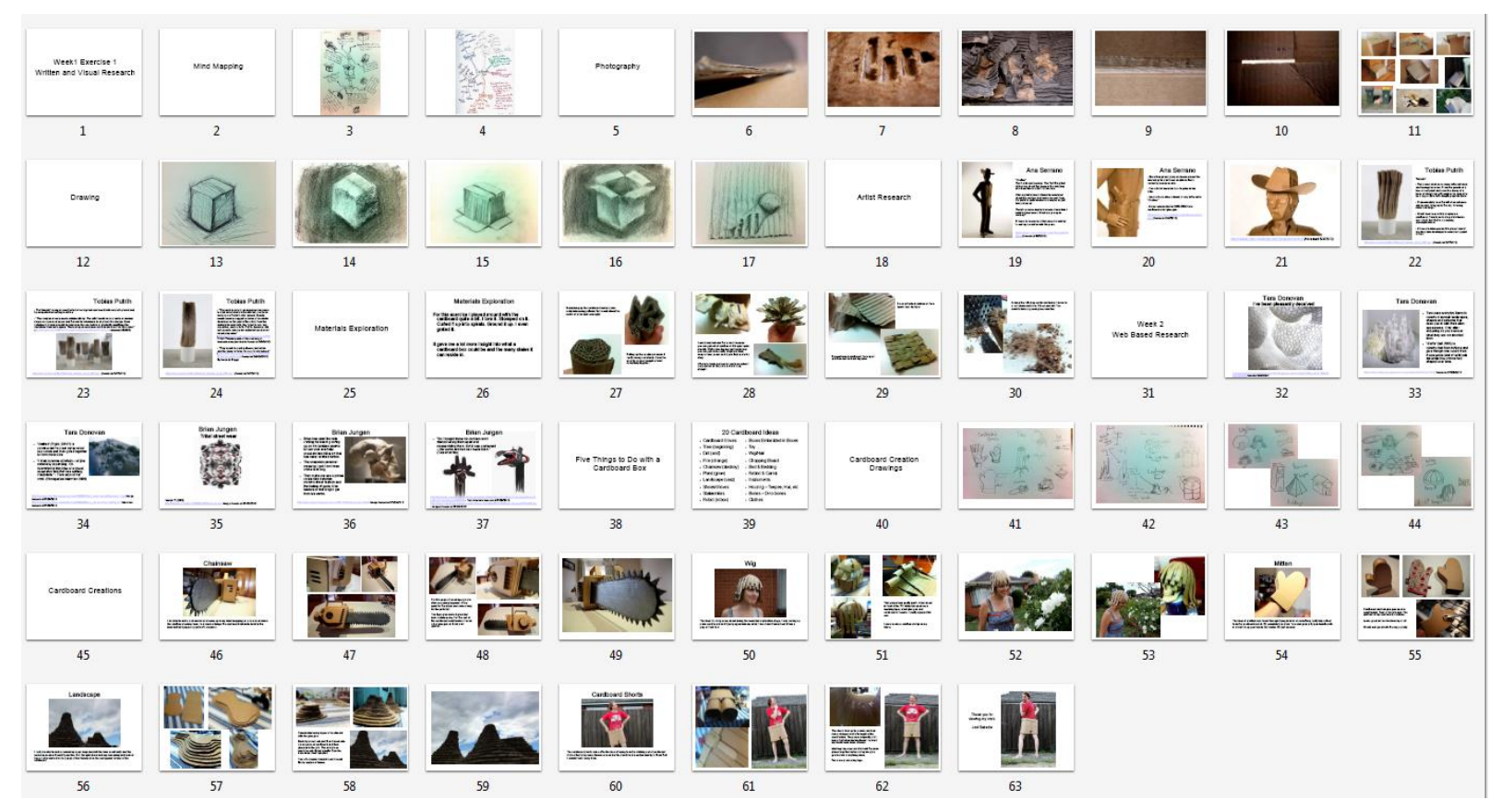

Figure 4: Student C exemplar, First Year Digital Presentation

Source: Curtin SoDA Art OUA_Student Learning Resources

If this form of presentation creates narratives that are too prescriptive or unambiguous for art education, then it is unavoidable. In this respect, for an online learner to create meaning and context, to show doing and thinking and to verify the authenticity of the artwork and themselves as author, essentially means that each digital image they create must be part of, or relate to, a larger narrative. It is worth highlighting though, that this notion of the visual art narrative has formed alongside digital technology. In Jonathan Gottschall's book The Storytelling Animal: How Stories Make Us Human, he emphasises that in our current technological age, we have a tendency to make non-fiction, fictiony. Everything from televised sports to upcoming elections are turned into stories, noting, "Story evolves. Like a biological organism, it continually adapts itself to the demands of its environment" (Gottschall 2012, 180). The storytelling aspect of art online learning does not diminish the meaning of an artwork/s but rather coincides with the technology of the day and enriches meaning through an alternative means of communication.

\section{Conclusion}

When assessing work via the digital image format, the assessor needs to consider the fundamental characteristics of the image in a digital space and how these can help to determine a suitable approach.

Often the differences between art online learning and traditional learning are dramatised as a conflict in which one is pitted as "better" or "worse". The rationale of the either/or approach is notably flawed because digital technologies help generate learning experiences that are different but not second-rate to traditional art education. In specifying this distinction, the following points have been established: the digital space may not enable a direct encounter with an artwork but this does not mean that an aesthetic experience is absent, the digital image may not be able to be forensically navigated in the same way as an artwork or a photograph but this does not mean that the authenticity of the artwork or its author is impossible to verify and the presentation of digital images may replicate a narrative but this does not mean that the narrative diminishes the credibility of the artwork.

When contemplating the question, "how do you assess an artwork online?", the answer must acknowledge the context and characteristics of the online space in contemporary education and that the evaluation of a work of art can never be independent of its digital mode of delivery. Online learning reflects the current technological advances and changing literacy of contemporary culture and those who are engaged in this mode of education can and must develop an understanding of this new type of visual literacy. In actuality this is occurring now and is exemplified by the model discussed in this paper. 


\section{REFERENCES}

Apkon, Stephen. 2013. The Age of the Image: Redefining Literacy in a World of Screens. United States of America: Farrar, Straus and Giroux.

Barthes, Roland. 2010. Camera Lucida: Reflections on Photography. New York: Hill and Wang.

Barrett, Terry. 2011. Making Art: Form and Meaning. New York: McGraw Hill.

Bryant, Antony and Griselda Pollock. 2010. Digital and Other Virtualities: Renegotiating the Image. London: I.B. Tauris \& Co Ltd.

Flusser, Vilém. 2013. Towards a Philosophy of Photography. London: Reaktion Books Ltd.

Gero, Robert. 2005. "The Border of the Aesthetic." In Art History Versus Aesthetics by Elkins, James. 3 -18. London and New York: Routledge, Taylor and Francis.

Gottschall, Jonathan. 2012. The Storytelling Animal: How Stories Make us Human. New York and Boston: Mariner Books - Houghton Mifflin Harcourt.

Hamzah, Mahizer and Adnan Abd Aziz. 2012. "Virtual Art Education: Is it Possible?". Distance Learning 9(1):29-35.

Johnson, Mark. 2007. The Meaning of the Body: Aesthetics of Human Understanding. London: The University of Chicago Press.

Rosen, Philip. 2001. Change Mummified: Cinema, Historicity, Theory. United States of America: University of Minnesota Press.

Sibley, Frank. 2001. Benson, John, Redfern, Betty and Jeremy Roxbee Cox, eds. Approach to Aesthetics: Collected Papers on Philosophical Aesthetics. Oxford: Clarendon Press. Kindle edition.

Sontag, Susan. 1977. On Photography. New York: Picador Farrar, Straus and Giroux.

Spalter, Anne Morgan and Andries van Dam. 2008. "Digital Visual Literacy". Theory Into Practice 47(2):93101.

Wilkes, Judith, Alexandra Cutcher and Susan Wilks. 2012. "Digital Technology in the Visual Arts Classroom: An [un]Easy Partnership". Studies in Art Education 54(1):54-65.

\section{ABOUT THE AUTHORS}

Dr Anna Nazzari: Anna Nazzari has a Doctorate of Philosophy (Art) and has worked at Curtin University for seven years in the field of online art education. In this environment she has been instrumental in advocating new modes of teaching and learning and in designing innovative course materials, such as a curatorial art stream and pathways in both painting and sculpture. Her research focuses on providing and implementing new avenues for art online education. Nazzari also has an on-going art practice, which thematically engages with notions of the absurd. In Albert Camus' 'The Myth of Sisyphus', the absurd is defined as an altercation between humanity's need for meaning and the visible meaninglessness of the world. Nazzari explores this premise by creating automated sculptural works that subvert how morality is accepted as a provider of truth in contemporary culture. Her artwork has been exhibited both locally and nationally.

Gina Cinanni: As Chair of OUA Studies in the School of Design and Art, Gina Cinanni is leading the future development of eLearning in art education in Australia. Cinanni has been involved in the delivery of online art education since 1999 and has been instrumental in the implementation and on-going development of the Fine Art degree.

Moira Doropoulos: Moira Doropoulos has been involved in art online education for the past ten years at Curtin University. Doropoulos is academic coordinator for the Fine Art major and is currently engaged in the further development of the third year studio practice pathway. She has also been instrumental in providing and implementing visual learning resources to assist in student centred learning. Doropoulos' art practice focuses on tradition, ritual and identity. She is engaged in the promotion of Western Australian textiles through the curation and development of international projects 